UDC 316.77:81'221

Mane KHACHIBABYAN

\title{
NON-VERBAL COMMUNICATION AND CUES IN ARMENIAN-AMERICAN LITERARY DISCOURSE
}

\begin{abstract}
Communication is foundation of life. Literature is a universal form of communication. Writers communicate beliefs, ideas, experiences, feelings and thoughts. Armenian-American literature is a huge source of communication. Armenian-American writers who migrated to the USA throughout various time periods bring unique storylines and techniques to literature. Nonverbal communication is known to be the more honest part of human communication. Understanding communication requires combined analysis of verbal and nonverbal communication. This research identifies features of nonverbal communication incorporated in literary texts. Nonverbal cues incorporated in literary texts are seemingly minor yet vital features which sometimes are left out of the readers' attention.

The following literary works were chosen for the research: Peter Balakian's Black Dog of Fate (1997, memoir), Micheline Aharonian Marcom's Three Apples Fell from Heaven (2001, fiction). The chosen samples include writings which have not been widely analysed especially from communication theory aspects. The main analysis method utilized was close reading of the texts. Further, research can be done to analyse poetry collections to identify whether nonverbal cues are as significantly used in poetry as they are used in stories and novels.
\end{abstract}

Keywords: communication, nonverbal communication, literature, Armenian-American writers, nonverbal cues, literary techniques, identity, pain of loss, exile, alienation.

Introduction

Communication is the foundation of life. Communication techniques differ from people to people, from nation to nation. Literature in this sense is a universal source of communication for the whole world. Literature communicates beliefs, ideas, experiences, feelings and thoughts. Each writer creates their own unique way of communicating with the readers through use of literary devices and language. Based on the writers' personal interests and experiences their writings change as well. Ar-
menian-American literature is a huge source of communication where multiple identities are encompassed. Armenian-American writers who migrated to the USA throughout various time periods faced a lot of cultural and historical problems which undoubtedly affected their writings.

Understanding communication is essential to successful management of human interactions. Communication is a significant field of study and research amongst theorists and scholars. Initially people associate communication with words and verbal interactions. How- 
ever, major studies along with people's experiences come to prove that a huge part of communication is nonverbal communication. Body and facial expressions have a massive role in transferring information, feelings and attitudes. Nonverbal communication tends to be the more honest part of human communication which is much harder to regulate and control than verbal communication. People have the skill of editing their thoughts and words before pronouncing those out loud, yet they haven't managed to have control over the micro expressions and body language. Understanding communication requires combined analysis of verbal and nonverbal communication. It is interesting that the features of nonverbal communication can vary from culture to culture. Many studies focus on identifying cultural specificities of each country concerning nonverbal communication.

Nonverbal communication has significant role in understanding ethnic identity. It is a crucial feature which gives cues about the personal and ethnic characteristics of people.

Literature as an essential form of communication has components of nonverbal communication. Many people do not pay close attention to nonverbal communication, especially when it's incorporated within literary texts. Different narratives reflect human body and its motion to convey additional meanings to the reader. Nonverbal cues incorporated in literary texts are seemingly minor yet vital features which sometimes are left out of the readers' attention. However, in case of thorough analysis one can identify the importance of those cues in every context.

\section{Literature Review}

Literature is an excessive means of com- munication. Authors communicate ideas and emotions through various forms of literature, using diverse linguistic, stylistic techniques and devices. Writers' personal or national background, their contextual experiences find their way into their literary works. Due to historical events, Armenians spread throughout the world forming the Armenian Diaspora, which has had a significant influence on the Armenian literature as well.

The United States is one of the countries where a great number of Armenian immigrants have found shelter. Not only after the Armenian Genocide, but before that as well, immigration to the USA and other countries has been common. Consequently, a new branch of Armenian literature formulated, which is known under the term Armenian Diaspora literature. Immigrant literature is an essential part of world literature, since it brought unique themes and feelings connected with homeland, individual and collective identity into literature. Many authors wrote about the life of Armenian-Americans and their literary contribution. In The Armenians in America (1977), Ara Avakian gives an overall introduction to Armenian history, people and immigration, focusing on cultural and national characteristics. According to the book more than $1,000,000$ Armenians live in America, most of whom are actively involved in education, arts, industry, economics, and other fields. The author represents Armenian Americans as strong and passionate people, who found shelter in America but never remained satisfied with simply surviving. They got busy in different fields, gained knowledge to be competent, established their church, created many organizations and NGOs, mainly preserved their language, were successful in science, art, etc. 
Other texts like The Magical Pine Ring: Culture and the Imagination in ArmenianAmerican Literature (1991) by M. Bedrosian and Literature of the Armenian Diaspora (1986) by Vahe Oshagan particularly focus on the analysis Diaspora literature and the issues that authors encountered while going through social changes. These writings also discuss the direct consequence of Armenian history on the Armenian-American literature, through literary analysis of Armenian-American poetry, fiction and non-fiction texts.

Vahe Oshagan sees Armenian Diaspora literature as ethnocentric, emotionally lyrical, moralizing, pseudo-realist poetry and prose. The key of this he sees in the language, its structure and importance in history of Armenian life. Another characteristic feature of Western Armenians, Oshagan believes to be their cosmopolitan ideology and cosmopolitanism. Many Armenian writers tried to transcend their national context and integrate with other nations and cultures. The reason of this Oshagan sees in the pain and experience of exile, which directly forced Armenians into other cultures.

The Magical Pine Ring includes a comparative study of how Armenian writers integrated to the "new culture" and how constant self-awareness effected on their literary writings. According to these sources ArmenianAmerican or Diaspora literature brings unique storylines into literature were feelings of exile, loss, diffusion, pain and alienation are registered. This part of Armenian literature has a lot to offer to its readers, and offers a totally different perception of Armenian literary discourse.

Kourken Mekhitarian in his work A Quarter Century of Armenian Literature Abroad
(1956) writes about the literature books and texts that were created outside of Armenia and belong to the so-called Diaspora literature. $\mathrm{He}$ talks about various authors and their literary heritage in a short chronological form. He characterizes Diaspora literature as literature about Genocide. He believes the pain numbed the writers and everything that they produced encountered post Genocide traumatic ideology.

Utilizing the information about Armenian immigrants and writers, this paper reflects and analyses Armenian-American literary texts. These texts serve as a foundation for exploring the subjects and themes of the works. To have a better understanding of Armenian-American literature this paper presents analysis of nonverbal cues that authors registered in their writings as ways to present their identity, adaptation to the new environment, feelings and emotions of grief, loss, alienation, etc. This paper also tries to identify the cultural features incorporated in nonverbal communication of Armenian Americans that found their way to literature.

Literature depicts society and its issues. The theories and researches in psychology and sociology consciously or unconsciously affect the writing style of authors. Writers themselves experience social issues, which are certainly revealed in their writings. Nonverbal communication is vital part of human communication. Nonverbal cues can transform much more intimate information about people's feelings and emotions than a thousand words. ArmenianAmerican literature lacks thorough research and appreciation. Immigrant writers have a lot to offer to world literature, with their unique approaches, themes and forms. Themes that cover social issues are subject of analysis not 
only from literary prospective but from sociological and psychological aspects as well. Nonverbal communication is present in every sphere of life. Writers integrate nonverbal cues in the plots of their stories to highlight the individuality of characters, create intimacy among the characters and between the text and readers. Applying theories of nonverbal communication and generally communication to literary texts will assist in thoughtful understanding of Armenian-American literature and the individual characteristics of the writers mirrored in their works.

Hall, J. A., \& Knapp, M. L. in 2013 and Hickson, M. in 2009 published different editions on Nonverbal Communication. Nonverbal communication is a widely-researched topic where new information is being uncovered rapidly by scholars. Both editions offer a comprehensive compilation of theory and research on nonverbal communication by classics and scholars. The volumes summarize significant studies of the field, as well as are both fresher scholarly theoretical and practical contributions to the field. In Nonverbal Communication (2013) the second section is titled "Focus on group membership," which was written by John F. Dovidio and Marianne LaFrance. The authors argue that nonverbal behaviours have significant consequences for race relations and inter-ethnic interactions in the context of ethnicity and race. Variances in nonverbal behaviour may be determined by socioeconomic, cultural and contextual influences. Due to this confusion, dislike and distrust can be produced in relations. The scholars explore ethnic and racial alterations in nonverbal skills and displays. This source assisted in overall summarizing the functions of nonverbal communication, more specifically referring to ethnic and cultural analysis of ArmenianAmerican writers and how they utilized nonverbal behavior in building intergroup relations between the characters of their stories. In Nonverbal Communication: Studies and applications (2009) the author provides us with an engaging and up-to-date introduction to the field through theory and practice. In the edition, various scholars and their ideas are represented. Nina-Jo Moore and Don W. Stacks utilize everyday life examples to demonstrate and help the readers to comprehend the effects of nonverbal communication on the world and communication. This information was used to analyze Diaspora literature and evaluate the influence of nonverbal communication on the characters.

The books Manwatching: A Field Guide to Human Behavior (Morris, 1977) and Kinesics and Context (Birdwhistell, 1970) discuss nonverbal communication centralizing the physical appearances of people and the motion of human body. Morris claims that people are obsessed with physical appearances and remain constant body watchers in any the situation. He came up with the concept of "manwatching" which argues the importance of observations in nonverbal communication. The main arguments of the books are that utilizing all the senses body decodes information and underlying meanings, the understanding of which depends on each individual and his or her personal perceptions, which vary based on various features. The texts offer the "man observes" practical ways of collecting data, observing, interviewing and decoding the human body signals within a certain context. Birdwhistell suggests various kinetic-linguistic exercises which teach how and what kind of data to look for. The idea of human observers ex- 
isted in literature since the start of modernism art with the term flâneur. People were becoming a subject of observation while they themselves were being observed. Many modernist writers and painters used such themes in their works. This paper applies the practical knowledge of body observation offered by these two scholars to Armenian-American literary texts in order to identify the writers' approaches to this subject. I will explore how characters observe each other and the world around them in creative texts, and what impact these observations have on the worldview formation of those same characters.

Paul Ekman, in his book Facial Expressions (1978) came up with several rules for managing and coping particularly with facial expressions/micro expressions. The rules include simulation (showing feelings when you have no feelings), intensification (giving the appearance of more feelings than you actually have); neutralization (giving the appearance of having no feeling when you really have a feeling); deintensification (giving the appearance of having less feelings than you actually have). Through Ekman's theory of facial micro expressions, this thesis explores how authors/writers incorporated facials in their works and what effects it has in conveying a certain emotion in a text.

\section{Research Questions and Methodology}

Literature as a source of communication cannot exist without nonverbal communication. Nonverbal cues strengthen the messages, are more honest and add up uniqueness and serve as a special technique of narration in literature. Armenian-American literature is a ground of unexamined nonverbal cues. Though most of the scholars who talked about the themes of American-Armenian literature highlight post-genocide pain and trauma as prevailing themes of Armenian-American literary discourse, this research intends to find more themes through the help of nonverbal cues that writers incorporated in their texts. Moreover, to identify nonverbal cues which are used to express the prevailing themes of ArmenianAmerican literary discourse. The research will once more highlight the essence of nonverbal communication in fully decoding messages. Understanding "literature-communication" will not be complete without careful examination of nonverbal cues. The main analysis will focus on nonverbal communication in Armenian-American literature and exploration of what sense it gives to the reader in addition to the literary techniques used by the author.

One fiction piece and a memoir were chosen for the analysis: Peter Balakian's Black Dog of Fate (1997, memoir), Micheline Aharonian Marcom's Three Apples Fell from Heaven (2001, fiction). The choice of the authors/books was done according to several criteria. Firstly, the mentioned authors are among the most critically respected writers in Armenian-American literary discourse. Secondly, the chosen samples include writings which have not been widely analyzed especially from communication theory aspects. The main analysis method is close reading of the texts.

\section{Research Findings and Analysis}

Armenian literature, like the nation itself is divided and fragmented. Due to the historical events Armenians spread throughout the world forming the idea of Diaspora. The United States was one of the many countries 
where Armenians found shelter. Armenian people quickly assimilated in the US society and got involved in the country's social, economic, education, arts and other fields. The urge to be successful and advance is one of the national/individual characteristics of Armenian people. Careful examination of their history is proof of this. Though American culture and life drastically differs from what Armenians experienced before, it did not prevent the Armenian immigrants from acculturating with the US society and becoming successful writers, doctors, lawyers, scientists and professionals in many other fields (Bedrosian, 1991). Armenian identity is a complex subject that almost never has a clear definition or image, especially in terms of the existence of the Diaspora. Armenians not only search for their individual identity but are also in great need of identifying national and/or cultural identity. All of this is reflected in the literature created both inside and outside of Armenia.

The theories and research in psychology and sociology consciously or unconsciously affect the writing style of authors. Authors themselves experience social issues, which are certainly revealed in their writings. Nonverbal communication is a vital part of human communication. Nonverbal cues can exchange much more intimate information about people's feelings and emotions than a thousand words. Diaspora writers have a lot to offer to world literature, with their unique approaches, themes and forms.

Armenian-American or Diaspora literature brings unique storylines into literature where feelings of exile, loss, diffusion, pain and alienation are registered. Armenian writers express their feelings of integration to a "new culture" in their works. Their constant self-awa- reness affected their literary writings and contributed the development of holocaust literature (Bedrosian, 1991).

Nonverbal cues, as in real one-on-one communication in literature as well can serve as source of more honest and strong messages. These cues add up to the plot and have a significant role in transmitting emotions to the reader.

Initially, Armenian literature presents chaos, religious and political conflicts, class and ethnic struggle, and language preservation struggles (Oshagan, 1981). Armenian literature developed through books and the press. The image of Armenians in America is blurry. This is because of the blurred and confused identity issues that people in the Diaspora were facing. Armenians have achieved considerable recognition for accomplishments in various fields.

Immigrant literature brought unique themes connected with homeland and collective and individual identity to world literature. The literary contribution of American-Armenian authors to Armenian literature is huge, yet not well appreciated and incorporated.

The Armenian Diaspora: Cultural Identity and Armenian-American Literature

When discussing and analysing texts presenting the Armenian American experience and how it's embodied to a consumer culture, it's significant to understand what Armenian American literature looks like nowadays. Many of the books by Armenian Americas or written about Armenians in America are memoirs, or fiction plots that were built up upon somebody else's memoirs or diaries.

Literature produced in Diaspora as a rule utilizes eyewitnesses or archival documents as the dominant source material of their stories 
(Mekhitarian, 1956). The narrative tones of the literary works that are set around the Genocide are deliberately meant to reserve a historically truthful voice. The Armenian Genocide has been fundamental to the society's cultural identity and memory. The terror of forgetting this history is plaited in Armenian American non-fiction and fiction works.

Genocide survivors still live in different parts of the world. Many Armenians who immigrated to America are either directly connected to a survivor or are caring for a survivor (Antreassian, 1981). The story of trauma, as a belated experience, demonstrates its boundless influence on a life. An urgent dilemma emerges as a crisis of traumatic narratives: Does the trauma come from encountering with death, or from the constant experience of having survived it?

The catastrophe of life and death following the Armenian Genocide outlines the Armenian American identity. Shared trauma assures some kind of unity in the community and stops the loss of cultural identity. The community cannot stand the death of their identity.

In Armenian Identity in a Changing World (2006), Levon Abrahamian contrasts the Armenian and Jewish Diasporas. If Armenians lost only their statehood which was, to some extent, replaced by religion, Jews lost their homeland after losing statehood. Only Western Armenians lost their homeland alike the Jews. However, even in this there is a substantial difference between the two kinds of Diaspora. This once again highlights the issue of homeland which is the central characteristic of the Armenian Diaspora. All this brings us back to the problem of the homeland, which seems to be the central characteristic of the Armenian Diaspora (326). Certainly, the loss of homeland was catastrophic whether it refers to Armenians descending from the East or West. Fractured families relied on the church and hoped to find reservation of the sense of homeland. The personal stories that showcase how Turkey exposed them to such crisis and suffering are often told in literary forms and often are filled with ancestral pathos, revealing the experiences of Armenian Americans.

For decades after the Armenian Genocide, Armenian immigrants, intelligentsia and community leaders were preserving the idea that the Diaspora would home come to Armenia. Denise Aghanian writes in The Armenian Diaspora: Cohesion and Fracture (2007), "Once diasporas are established, they become intimately shaped by the host country's dominant ideology, political system, socio-economic structure, cultural traditions and domestic foreign policies" (Aghanian, 2007, p. 5).

Due to the hybridity of diasporic identities, the tendency to pick and control cultural characteristics is real-world inescapability for Armenian Americans. Political, religious and cultural leaders ensure to preserve cultural and national values in the Diaspora. One way to do this is through consciously positioning the Genocide as a shared cultural memory in order to maintain the unity of the community.

A significant part of the Armenian Diaspora, which is assessed to be somewhere in the range of five to ten million in number, is caused by the Armenian Genocide. Amid and after the Genocide of 1915, Armenians were distributed to nations like Lebanon, Greece, Iran and Iraq to locate a sheltered place to live with their families. Around the mid-twentieth century, when clashes emerged in the nations where they were living as refugees, Armeni- 
ans had to relocate and they found their way to America. Many of the Armenian Americans have had the actual experience of being doubly-uprooted, carrying with them their Armenian inheritance and in addition the traditions and customs adopted from temporary home countries. Undoubtedly, the multitude of diasporas added to the trouble of finding a solitary ethnic portrayal of Armenian-ness and Armenian American-ness.

"Diaspora identities are those that are constantly reproducing themselves through difference. As such each Diaspora community has modified its way of life, blending elements from its heritage with elements of the mainstream. The use of English in the Armenian Apostolic Church is a clear example. Even so, within their travels and hyphenated identities there are more complex markers of identity. This means keeping any values and customs from other groups. By the use of transnational strategies, which exposes them to many cultures, Diasporas are in an advantageous position to pick and choose characteristics," states Aghanian in her work summing up her views on diasporic identities (Aghanian, 2007, p. 177).

\section{Parenthood and Armenian Genocide}

Families are social structures that develop and maintain the socialization and value system for younger members of the community. Thus, it is not surprising that during wars adults are the first ones that fall under pressure. As well as, attackers aim to dissolve families and separate children. Parenthood is especially tough during war times and the Holocaust as well. Under the extreme circumstances of the Armenian Genocide parents transmit emotions and feelings to their children which later have huge enormous impact on their formation of worldview. Of course, it cannot be assumed that these transitions have only positive value. Parenthood itself has many functions. Parents are responsible for social, psychological economic and physical needs and desires of children. The types of caring and looking after children may differ within and between cultures. A serious question arises regarding the Armenian Genocide or Holocaust. What happens when the capacities of parents are extremely impaired, due to massive destruction? As a result of Armenian Genocide hundreds of thousands of families were destructed and could not go on functioning within their homes, according to their social status and customs.

Many parents who survive wars are found to be emotionally inaccessible to their children's sensitive needs, probably because of the link between problems of nurturance and their incapability to grieve their dead. Anxious with the issue of life and death, parents often suffer from emotional state of self-hatred and insignificance. Studies have observed at communication styles within families of survivors (Baron \& Chaitin, 2001). Two main patterns where identified in the behaviour of survivor-parents. Some survivor-parents either extremely exposed their children to their horror stories, or otherwise, were silent about their emotions and experiences, through "guilt-inducing, nonverbal and indirect styles of communication with their children" (Bar-on \& Chaitin, 2001).

These forms of communication frequently scare the children. This might lead them to better engage with their fantasies which can be very extreme. Moreover, children might also develop troubled psychological states. In any case through communication pattern, parents 
transmit their own traumas to their kids. Often survivor-parents send out assorted messages to their children. Some children are simultaneously told that it is important to enjoy life as they constantly are reminded of the mourning the dead. Other survivors criticize their children, while telling them that they children were the survivor's only reason for living. In other scenarios, the children get the hint that they have to continually remember the past and grieve, while their parents reject to talk about it. Other survivor-parents are known to reflect their aggressive fantasies onto their children, thus unconsciously inspiring children to be overly violent. Likewise, many parents convey their distrust towards the external environment to their children, indirectly teaching them to fear the people beyond of their family unit. The silence between the survivors and their children regarding their traumatic experiences originated not only from the parents' necessity to disremember and forget the past and to assimilate to new community, but also from parents' belief that cover up of information about the horrors of the Armenian Genocide are vital for their children's normal psychological development. Their children, however often turn out to be sensitive to parents' need to keep silence about certain experiences. As a result, a "double gate" of silence establishes, which is equally maintained by both generations: parents simply don't talk and children don't ask (Bar-on \& Chaitin, 2001).

It is not a coincidence that many American-Armenian writers write their literature based on their survivor-parents' personal memories or based on diaries or documents of their acquaintances. Growing up in Diaspora Armenian Americans are constantly exposed to the problem of Armenian Genocide.
Themes of Pain of Loss, Exile, Alienation Represented through Literary Devices and Nonverbal Cues in Armenian-American Literature

Most of the American-Armenian writers were highly influenced by the historical events which forced Armenians to leave their homeland and spread throughout the world, despite the time period they lived in. ArmenianAmerican writers discuss various themes like life, love, identity, family, pain or any other topic in their poetry and prose. Yet consciously or unconsciously the tragic historical events somehow find their way into the narrative. Armenian Americans have created literature that reflects the heritage of anxieties and fears. Likewise, the Armenian American scholars inclined to emphasize their analysis on the powerful historical memory of Armenian Genocide.

Three Apples Fell from Heaven by Micheline Aharonian Marcom is a poetical novel telling about vanishing of a village during the Armenian genocide in 1915. The novel is set in the years of the Ottoman Turkish government's acts of brutality. Those acts resulted in the deaths of more than a million Armenians. These historical tragic events are foundation of this novel. Myung Mi Kim, a Korean American poet reviewed the book writing: "Not to have seen it yet inheriting it," (Aharonian, 2001). And indeed, Armenian-American writers showcase, retell and transfer the history of their nation without seeing it, yet the saved documents and eyewitnesses are a firm foundation for depiction. The book is developed through series of chapters which utilize the stories of characters like Anaguil (Armenian girl saved by Turkish neighbours, lost her 
parents and views the world through a Muslim veil), Sargis (a poet hidden in his mother's attic, dressed as woman and going mad), Lucine (a servant, lover of the American consul), Dickran (an infant left under a tree on the long evacuation from an Armenian village, who dies with his name unrecorded). Through these character's stories the reader witnesses the disappearance of people.

Writing was a key tool for the victims to record crime and preserve the history. Armenians who survived the massacres, utilized writing as a vital instrument to reach to wider audiences. There are endless volumes of eyewitness accounts and interviews, memoirs, journals and diary writings that depict life of the Armenian people before and after the catastrophe. Writing of such autobiographies and memoirs particularly developed in the 1920s 1930s (Cheterian, 2015).

The second chapter "An Omelette for Mama," of Three Apples fell from Heaven starts with the following description: "She walks in the direction of the well now... She does not look to it or breathe more quickly into the late morning air which is no longer still but bustling... She speaks underneath her breath, pushes the words to the packed and uneven stones in front of her booted feet. She stares at the ground and at the tips of her shoes as they leave no dusty impressions. She whispers..." (Aharonian, 2001, p. 1) As one might notice, much importance is given to the way character looks around and gazes. Nonverbal cues left in quotes like this, and the ones that I will showcase in the further paragraphs add up additional meaning to the text and strengthen the characters' emotional experiences. Another quotes in the further pages of the book show the importance of describing facial features in litera- ture: "As she continues walking on the dull marble earth, she sees the hoary mole on Eghis Hanim's left cheek below her lower eyelashes; a protuberance of disclosed dark skin rises above the woman's pale flesh, pushing her left eye upward and making it smaller." (Aharonian, 2001, p. 5).

As Paul Ekman discusses in his book $\mathrm{Fa}$ cial Expressions (1978), people often give the appearance of having no feelings when they really have one. Ekman categorized these kind of nonverbal cues as neutralization (Ekman, 1978). Aharonian incorporated silence and "quietness" in the text as form to express neutralization. For instance: "Khalil Agha reaches across the table to take the currency. As he begins to remove the coins from her hand, he runs his fingers down the center of her palm. He slowly glides his fingers along each of the red moons..." (Aharonian, 2001, p. 8).

As Morris discusses in Field Guide to Human Behavior (1977) "manwatching" has great importance in decoded body messages which tend to give out truthful information about people's intentions. In the text Aharonian used gazing and staring for enriching character's feelings. "The egg-seller's gaze is drawn toward her bitten fingers where only small stubs of fingernail remain." (Morris, 1977, p. 10); “Anaguil enters the kitchen quietly and remembers that today they will go to the hamam." (Morris, 1977, p. 19). Later, Aharonian wrote: "Her hands are red and chapped, her brown hair falls to her waist in one loosely bound plait. She talks beneath her breath and upon hearing Anaguil raises her head and smiles slightly. She lifts her arm and waves a hand up and down, like clumsy bird slipping from level to level" (Morris, 1977, p. 19). This can be considered as deintensification (Ekman, 
1978) when people give the appearance of having less feelings than they actually have. Slightly smiling, raising head, looking away and such descriptions of gaze may, in some context, express fear, pain and in some context deintensification. "Anaguil looks and thinks, she bites at the hard edges of her finger" (Morris, 1977, p. 20 ). Other samples of quotes that have nonverbal cues are: "All of this is private, silent until it breaks outside of her a little, and then a little bit more, bit by bit the laughs erupt like unstoppable streams from Anaguil's throat, her tongue, her teeth, her cracked lips. She laughs out loud" (Morris, 1977, p. 22); "For Anaguil it is impossible to notice how her shoulders stiffen and her arms lock during the hours they spend there" (Morris, 1977, p. 22); "Anaguil nods her head" (Morris, 1977, p.23); "Hagob gazes at his feet as he walks and stumbles when the man to his left or right jerks him" (Morris, 1977, p. 128).

Black Dog of Fate (1997) is a memoir by Peter Balakian. The story showcases Balakian's journey through life. He is attempting to discover his roots and identify the fate of the Armenians. Utilizing undisclosed stories, recorded documents, poetry, lost artefacts and family stories Balakian pieces together his family history, discusses the Armenian genocide and finds out that the past greatly impacted the present and future. This book is not a story of hope or about recognizing the ethnic heritage. It is rather a story of anguish, loss, grief and fear: condemning the empire that committed such acts towards Armenian nation. The narrator strives to understand victimization, and tries to identify the power the past and its influence on people.

Nonverbal communication fully decodes messages that are communicated. Very often people do not pay attention or ignore nonver- bal cues in both oral (face-to-face) and written communication. The authors highlight the importance of paying attention and offer some practical ways of spotting those cues. "My grandmother walks ahead of my aunt... she is dressed navy or beige...Mu aunts are dressed in white or pale-blue linen suits. Silk blouses, silk scarves. They wear gold earrings, pearls." Morris in Manwatching (2012) discusses dressing and colours as part of nonverbal communications. In Black Dog of Fate very often the reader gets description of dressing and colours which correspond to the character's feelings and state.

Ares in World without Words (2012) discusses the importance of ability to watch and correctly define the nonverbal messages. Often these messages are silent but talk more than the words would. "Every day our extended family would sit around dining room....and my grandmother quietly watching" (Ares, 2012, p. 4); "Through her thick lenses she looks serious. And sometimes I stare at the dark, wrinkled half-moons beneath her eyes" (Ares, 2012, p. 8); "My grandmother's big brown eyes keep watching me intently" (Ares, 2012, p. 18). These descriptions give out and stress the emotional experience that characters are going through.

Hall in Nonverbal Communication (2013) presents nonverbal communication from various aspects. In analysing non-verbal cues individual and group membership are the two most important facets. It is interesting how literary texts presents their characters from individual point and then in the group. Later the readers can see this through some parts in the chapters of Black Dog of Fate: "Leaning over the counter in my oxford button-down, white chinos, and stuffed bucks, it always flashed through my mind..." (Hall, 2013, p. 10); "My grandmother 
nodded at me as if to confirm my comprehension then there was silence" (Hall, 2013, p. 12). "My grandmother looked around the kitchen and then looked me square in the eyes, as if she was about to attack a melon with her hands to see if it was ripe." (Hall, 2013, p. 14); "On these walks my grandmother liked silence, but when she talked, she talked about stock markets or Yankees" (Hall, 2013, p. 20). Silence is the most used nonverbal cue both in Black Dog of Fate and Three Apples Fell from Heaven.

Approximate characteristic breakdown of Armenian-American literature can be formed after close reading of the works by Peter Balakian (Black Dog of Fate), Micheline Aharonian Marcom (Three Apples Fell from Heaven). The themes of thesenovel and memoirs overall evolve through several phases:

Phase 1: Leave the Old World

Phase 2: Journey to the New World (the USA \& modern culture)

Phase 3: Shock, resistance, exploitation, and discrimination (immigrant experience/minority experience)

Phase 4: Assimilation to dominant American culture and loss of cultural/ethnic identity

Phase 5: Rediscovery or reaffirmation of ethnic identity.

Authors themselves go through these stages and experiences the reflections of which the reader sees in their literary writings. Literary works register interesting plots and storylines, at the same time bringing the pain of exile, loss, and alienation into the texts. It's essential to identify how writers incorporated nonverbal cues which communicate the themes of grief, loss, alienation in their works. Based on the discussion above nonverbal communication is not only important in real life communication but also in literary discourse as well. Nonverbal cues are widely integrated in the plot of the stories that convey additional information about the characters' experiences.

\section{Limitations and Avenues for} Future Research

Armenian-American and overall Armenian Diaspora literature is enormous. Diaspora literature is a vital part of Armenian literature since it showcases the nation's history and experience through various stylistic and literary techniques. Literature always needs re-examination and deep analysis from various aspects. Particularly, Armenian-American literature that is so complex in its nature. Readers pay close attention to the descriptive writing styles or literary devices used by the authors. However, they do not usually consider nonverbal cues as part of the literary techniques. Silence, staring, looking away and any other mentioning of nonverbal cues in literary plots are significant features that definitely convey additional meanings to the readers. This capstone analyses fiction and nonfiction pieces. Further, research can be done to analyse poetry collections to identify whether nonverbal cues are as significantly used in poetry as they are used in stories and novels.

\section{REFERENCES}

Abrahamian, L. (2006). Armenian Identity in a Changing World. Mazda Publishers.

Andersen, P. A. (2007). Nonverbal communication: Forms and functions (2nd ed.). LongGrove, IL: Waveland Press. Antreassian, J. (1981). The Armenian in America: A Personal Viewpoint. The Armenian Image in History and Literature. Malibu, CA: Undena Publica- 
tions.

Ares, E. B., \& Camping, J. (2012). World without Words. Amsterdam: Hogeschool van Amsterdam.

Avakian, A. (1977). The Armenians in America. Minneapolis: Learner Publications Company.

Aghanian, D. (2007). The Armenian Diaspora: Cohesion and Fracture. University Press of America.

Balakian, P. (1997). Black Dog of Fate.Basic Books.

Bar-on, D. \& Chaitin, J. (2001). Parenthood and the Holocaust. Yad Vashem.

Bedrosian, M. (1991). The Magical Pine Ring: Culture and the Imagination in Armenian-American Literature. Detroit: Wayne State University Press.

Birdwhistell, R. L. (1970). Kinesics and Context. Philadelphia: University of Pennsylvania Press.

Cheterian, V. (2015). Open Wounds: Armenians, Turks and a Centruy of Genocide. Oxford University Press.

Ekman, P. (1978). Facial Expression.In A. W. Siegman \& Feldstein (eds.), NonverbalBehavior and Communication.Hillsdale, NJ, Erlbaum.

Ekman, P. (1978). Facial Expression.In A. W. Siegman \& Feldstein (eds.), Nonverbal Behavior and Communication. Hillsdale, NJ, Erlbaum.

Hall, J. A., \& Knapp, M. L. (2013). Nonverbal Communication. Berlin: De Gruyter Mouton.

Kherdian, D. (2008). Forgotten Bread: FirstGeneration Armenian American Writers. Berkeley, CA: Heyday Books.

Marcom, M. (2001). Three Apples Fell from Heaven. New York: Riverhead books.
Mekhitarian, K. (1956). A Quarter Century of Armenian Literature Abroad.

Morris, D. (1977). Manwatching: A Field Guide to Human Behavior. New York, Harry N. Adams.

Oshagan, V. (1986). Literature of the Armenian Diaspora. Board of Regents of the University of Oklahoma.

\section{ANNOTATED BIBLIOGRAPHY}

1. Andersen, P. A. (2007). Nonverbal communication: Forms and functions (2nd ed.). LongGrove, IL: Waveland Press.

Peter Andersen $(\mathrm{PhD})$ is author of over 150 book chapters, journal articles, research papers and five books. He is one of the established scholars in communication field. Andersen, in his book Nonverbal Communication: Forms and Functions, presents existing research and theories in nonverbal communication. The work is conceptually organized around key functions (power, intimacy, and deception), uses and purposes of nonverbal communication. The volume introduces the reader with nonverbal message codes and cues; biological and cultural differences; neurophysiological features. The book has 12 chapters, where author examines the functions of nonverbal reactions and impact of stress, anxiety, emotion, communication avoidance, etc. One whole chapter is devoted to the analysis of expressions and nonverbal cues in the scope of cultural differences. Deception and its detection through communication codes and nonverbal cues is also thoroughly discusses in the book. Overall, the text describes how nonverbal behaviour can communicate anxiety, affection, persuasion, power, deception, intimacy, gender and culture. 
2. Ares, E. B., \& Camping, J. (2012). World without Words. Amsterdam: Hogeschool van Amsterdam.

The information exchange through nonverbal expressions and gestures has significant role in social interactions. This is a subject of excessive scientific study. The subject has been studied from various angles, including analysis of how non-verbal communication is relevant to interpersonal relations, how it helps to incorporate societies, etc. This book offers a collective study of nonverbal communication focusing on cross-cultural features. It consists of various chapters. Initially the book gives an introduction to nonverbal communication and body gestures. Then it talks about cross-cultural communication. A separate chapter is devoted to facials. The last chapter discusses cross-cultural communication referring to approximately 22 countries.

The book has a section which is devoted to written nonverbal communication, which is the major part I will use from this source. Nonverbal communication fully decodes messages that are communicated. In the section, it is stated that nonverbal communication has its significant role in written communication as well, let it be professional/academic or creative writing. Very often people do not pay attention or ignore nonverbal cues in both oral (face-toface) and written communication. The authors highlight the importance of paying attention and offer some practical ways of spotting those cues.

3. Avakian A. (1977). The Armenians in America. Minneapolis: Learner Publications Company.

This book discusses Armenian people and their history. The author narrates the history of Armenians introducing the national and cultur- al characteristics to the readers in the first part of the book, including: origins, religion, language, political and economic history, society, population, culture. Armenia very frequently was under foreign suppression and domination. The historical events, especially in $19^{\text {th }}$ century lead to slaughtering of Armenians by Turks, which is why many people had to flee to stay alive. The entire population was forced to leave their homeland by Turkey. A considerable number of Armenians live in America, nearly 500,000. The United States was a hospitable country for a lot of people who were in search of freedom and were striving to survive. The immigrants were courageous, industrious, skillful in crafts and trades. They very quickly adapted with the "new home" and throughout years improved their education and practical skills. They became artists, merchants, lawyers, doctors, engineers, scientists, teachers, etc., having their input in the development of American economic, industrial and cultural life.

The second part of the book discusses the Armenian Immigration to America starting from early 1620 to 1924 and up to recent years. The third one focuses on Armenians and their life in America. It particularly presents the distribution of the population, occupations, social/cultural life, and the integration of the people into American life. The final chapter concentrates on the language, church and assimilation.

4. Birdwhistell R. L. (1970). Kinesics and Context. Philadelphia: University of Pennsylvania Press.

Ray Birdwhistell is an anthropologist and expert on human communication through body motion. He terms his study as kinesics, meaning human body motion. The central idea of the research is the theory that human commu- 
nication requires and utilizes all the senses. As well as states that gestures and movements are coded differently depending on the individual and his/her cultural background. At last he offers ways and skills through which movements can be decoded within a particular context.

The book consists of 5 parts, which are the following:

- Learning to Be a Human Body

- Isolating Behaviour

- Approaching Behaviour

- Collecting Data

- Research on an Interview.

The first part starts the discussion from child years. The author claims that the analysis of human body should start from childhood through filming their behaviour. The family, masculinity and femininity as display have their huge role in this. The second part is about some particular gestures and signals; "redundancy" in multi-channel Communication. The third section is reflecting the social contexts of communication; and offers more analysis on American movement and speech. The forth is offering practical ways of observing and interviewing the body signals. It suggests how and what kind of data to look for. The text talks about head nods specifically. The final one continues the discussion of the theme through various kinetic-linguistic exercise and examples.

5. Ekman P. (1978). Facial Expression. In A. W. Siegman \& Feldstein (eds.), Nonverbal Behaviour and Communication. Hillsdale, NJ, Erlbaum.

This book offers thorough research on nonverbal communication by referencing various authors and theorists of the same field. It consists of several chapters each of which refers to a specific theme/aspect of nonverbal com- munication. One of the sections of the volume is about facial expressions and their significance in conveying emotions. Paul Ekman is one of the greatest theorists and psychologists of the field who established a special center which is centered on facial expressions. Ekman is the author of many books that encourage the study of micro expression. He believes that through understanding these "signals" one will be fully be able to decode and make sense of the conveyed information and emotions. Ekman suggested five rules for managing and coping with facial expressions:

- Simulation: showing feelings when you have no feelings.

- Intensification: giving the appearance of more feelings than you actually have.

- Neutralization: giving the appearance of having no feeling when you really have a feeling.

- Deintensification: giving the appearance of having fewer feelings than you actually have.

6. Hall, J. A., \& Knapp, M. L. (2013). Nonverbal Communication. Berlin: De Gruyter Mouton.

Nonverbal communication is a widelyresearched field. New information is rapidly uncovered about nonverbal communication in human transactions by scholars. The actual volume was written by a social psychologist and communication scholar. This book is a comprehensive compendium of theory and research on nonverbal communication by authors from eight countries. The scholars are from various backgrounds (anthropology, communication, psychology, psychiatry, linguistics, and counseling). Overall, the volume is a huge contribution to scholarly research available today on human behavior. It offers practical applications 
and methods of applying this knowledge to everyday life as well.

The book is divided into seven sections:

- Introduction

- Fundamental perspectives

- Modalities of nonverbal communication

- Focus on the individual

- Focus on the dyad

- Focus on group membership

- Settings

The section "Focus on group membership" is written by John F. Dovidio and Marianne LaFrance. The authors of the chapter argue that nonverbal behaviours have significant consequences for race relations and interethnic interactions in the context of ethnicity and race. Variances in nonverbal behaviour may be determined by socioeconomic, cultural and contextual influences. Due to which confusion, dislike and distrust can be produced in relations. The chapter focuses on the role of nonverbal communication within the context of Black-White interactions in the USA. The scholars explore ethnic and racial alterations in nonverbal skills and displays. The text states that nonverbal behaviour has major importance in signalling the quality intergroup communication. It further defines how a complete understanding of non-verbal behaviour can benefit the dynamics of intergroup relations and create more efficient and harmonious interactions. I will use this chapter to reflect the ethnic and race differences in nonverbal communication by referring to Armenian-American's and their identity, since they had to adapt to a "context" very different from their homeland. I will further analyse how this adaptation and changes in their personality affected their works and the way they utilize non-verbal behaviour in building inter- group relations between the characters of their stories.

7. Morris D. (1977). Manwatching: A Field Guide to Human Behavior. New York, Harry N. Adams.

Desmond Morris is etiologist, zoologist, surrealist painter, and famous author in human socio-biology. This volume is a catalogue of human behaviour, including: gestures, postures, facial expressions, clothing, and descriptions of the underlying causes and meanings. The author offers comprehensive research on nonverbal communication. Body language is the core of nonverbal information. Emphasizing its role D. Morris wrote: "Whether we realize it or not. We are all obsessed by with physical appearances. Even when we are engaged in a lively conversation and seem to be engrossed in purely verbal communication. We remain ardent body watchers." Great part of human interaction is what Morris calls "manwatching." Human beings are constant observers while they themselves are being observed by others. This observation is an essential part of nonverbal behaviour. Signals, codes and cues that people get from those observations can be interpreted differently depending on the understanding of the individual. That is why so many studies try to offer patterns and decoding skills for enhancing communication.

8. Bedrosian M. (1991). The Magical Pine Ring: Culture and the Imagination in Armenian-American Literature. Detroit: Wayne State University Press.

Margaret Bedrosian study examines the on-going consequence and impact of Armenian history on Armenian-American writing. She uses the works of ten Armenian-American including poetry, fiction and non-fiction texts, to reflect the continuing influence on Armenian 
Americans. She discusses the cultural symbols, attitudes and myths that were inherited from the "Old World." She also offers comparative study, discussing how two cultures come together, integrate and conflict in the imagination of the writers.

The Magical Pine Ring offers an understanding of concerns that Armenians' as immigrants have. As well as talks about the impact of self-awareness regarding the adaptation to
America and its life. This volume offers through analysis of Armenian-American writers and the themes of their texts. Due to the works of those writers America gets to know the real Armenian diaspora. Literary works register interesting plots and storylines, at the same time bringing the pain of exile, loss, alienation into the writings. That is why Armenian-American literature stands out from what Armenian literature is supposed to be. 